\title{
A Retinal Tear Induced By Pazopanib Therapy: A Case Report
}

\author{
Raza Hasan, MD \\ Thomas Jefferson University, raza.hasan@jefferson.edu
}

Follow this and additional works at: https://jdc.jefferson.edu/tmf

Part of the Medicine and Health Sciences Commons

Let us know how access to this document benefits you

\section{Recommended Citation}

Hasan, MD, Raza (2015) "A Retinal Tear Induced By Pazopanib Therapy: A Case Report," The Medicine Forum: Vol. 16 , Article 13.

DOI: https://doi.org/10.29046/TMF.016.1.012

Available at: https://jdc.jefferson.edu/tmf/vol16/iss1/13

This Article is brought to you for free and open access by the Jefferson Digital Commons. The Jefferson Digital Commons is a service of Thomas Jefferson University's Center for Teaching and Learning (CTL). The Commons is a showcase for Jefferson books and journals, peer-reviewed scholarly publications, unique historical collections from the University archives, and teaching tools. The Jefferson Digital Commons allows researchers and interested readers anywhere in the world to learn about and keep up to date with Jefferson scholarship. This article has been accepted for inclusion in The Medicine Forum by an authorized administrator of the Jefferson Digital Commons. For more information, please contact: JeffersonDigitalCommons@jefferson.edu. 


\section{A Retinal Tear Induced By Pazopanib Therapy: A Case Report}

Raza Hasan, MD

\section{INTRODUCTION}

The management of renal cell carcinoma has undergone major transformation in recent years. With the onset of innovative surgical treatments and systemic medications - there has been an overall decrease in mortality. ${ }^{1}$ The systemic medications that target the vascular endothelial growth factor (VEGF) protein have created the most potent effects, especially when treating metastatic renal cell carcinoma. These prove to be important treatments since renal cell carcinoma has become the seventh most common cancer in men, with a general prevalence of $2-3 \%{ }^{2}$ With more advancement in knowledge about renal cell carcinoma, research has shown the utility of pazopanib (Votrient), a specific tyrosine kinase inhibitor, targeting multiple receptors; its action is primarily to block angiogenesis and tumor growth, such as VEGFR-1, VEGFR-2, VEGFR-3, PDGFR-A, PDGFR-B, FGFR-1, and FGFR-3. ${ }^{3}$ Targeting these specific receptors helps pazopanib to achieve an overall clinical benefit rate of greater than $90 \%$, creating long-lasting disease control for patients

\section{CASE PRESENTATION}

A 63 year old Caucasian female with a past medical history of migraine headaches, dyslipidemia and depression was diagnosed with clear cell type Renal Cell Cancer, in late 2004. She underwent a laparoscopic nephrectomy in 2005 and a kidney mass measuring $9 x$ $7 \times 4 \mathrm{~cm}$ was removed, revealing T2 disease with Furman Grade 2 disease. The patient was followed for years and had a CT scan of her Chest in June of 2012 - where multiple bilateral pulmonary nodules were identified, the largest nodule was a $1.5 \times 1.2 \mathrm{~cm}$ nodule at the right middle lobe. CT-guided biopsy was attempted, however was not diagnostic. Therefore, the patient underwent a right upper lobe wedge resection in October of 2012 , which confirmed metastatic renal cell cancer to the lung. A PET/CT scan was also performed, and ruled out any evidence of abdominal or bone metastatic disease.
Additional therapeutic options were discussed with the patient, such as high-dose interleukin-2 infusion to achieve durable remission and then potentially start targeted therapy when needed. At the time when she was diagnosed with metastatic disease, the patient was in optimal health and was an excellent candidate for high-dose interleukin-2 treatment because she only had pulmonary nodules, without evidence of metastatic disease elsewhere in her body. She was agreeable and finished three cycles of high-dose interleukin-2 treatment along with Stereotactic Body Radiation Therapy. The patient was finally started on targeted therapy with a multi-tyrosine kinase inhibitor in June of 2013. Pazopanib $400 \mathrm{mg}$ daily was started and titrated up to $600 \mathrm{mg}$ daily, which is considered optimal therapy. However, this patient began to have significant diarrhea without relief from Lomotil and other antidiarrheal medication regimens. Her dose was decreased to $400 \mathrm{mg}$ daily which resulted in a decreased amount of diarrhea - one to two times a day which was tolerable. Additionally, a few months after the onset of pazopanib treatment, the patient began having blurry vision, a symptom which was very worrisome.

\section{DIFFERENTIAL DIAGNOSIS}

The patient's blurry vision was the main symptom of concern - her vision had been gradually worsening since the start of pazopanib therapy. Therefore, it was suspected that the systemic therapy was a plausible causal agent of the blurry vision. Upon visiting the ophthalmologist, she was diagnosed with Rhegmatogenous Retinal Tear OD. Her past ocular history was negative for any prior chronic diseases. On exam, the patient had retinal detachment, superotemporal (horseshoe) tear. Furthermore, the patient's left eye exam was remarkable for nuclear sclerosis. It was likely determined that the pazopanib caused a tear in the retina, thus further leading to detachment 


\section{The Medicine Forum, Vol. 16 [2015], Art. 13}

\section{OUTCOME AND FOLLOW-UP}

To treat the pazopanib induced retinopathy, the patient had a pneumatic retinopexy performed on August 19, 2014 and was started on Maxitrol 0.1\% 1 drop OD, four times a day. Post operatively, she had decreased complaints of blurry vision. However, because of this adverse event along with intractable diarrhea, the patient was switched from pazopanib to Sutent $37.5 \mathrm{mg}$ daily. The Patient is currently doing well - the blurry vision has not worsened and is slowly improving after stopping pazopanib.

\section{DISCUSSION}

The usage of pazopanib is a common treatment in metastatic renal cell carcinoma. A multitude of studies have shown that "pazopanib demonstrated significant improvements in progression-free survival and response rate compared with placebo in patients with advanced or metastatic RCC."7 Furthermore during these studies, there were no reports of patients developing other systemic abnormalities; the medication demonstrated acceptable safety and tolerability. However, as pazopanib is an oral angiogenesis inhibitor targeting specifically VEGF receptor, it is important to evaluate other locations in the body that might be affected secondary to inhibiting VEGF receptors.

A recent study was published evaluating the ocular effects of Sorafenib - as it was shown that many cancer signaling molecules, such as VEGF, were also expressed in ocular tissue. 5.6 Sorafenib and Pazopanib have similar pathways, both specifically targeting VEGF proteins and thus both affecting the ocular tissue. Furthermore, there have been studies analyzing the effect of pazopanib in mice retinal tissues - specifically studying pazopanib's effect on inhibiting choroidal neovascularization. It was shown that pazopanib primarily down-regulates the VEGF release in the retina and impairs VEGF-induced signaling and chemotaxis. ${ }^{8}$ Thus, a clear link is illustrated between pazopanib and its effect on retinal tissue. Furthermore, studies have shown that if pazopanib is "orally administered, [it] has good bioavailability to the retina/choroid" further giving proof to its profound effect on the retina and likely impact on treating ocular abnormalities, such as choroidal neovascularization by inhibiting angiogenesis. 9.10
However, analysis of the link between pazopanib and retinal tears is important to be determined - in order to understand the findings in this case. Case reports of retinal effects from Sorafenib have been reported, likely secondary to a similarity between the VEGF receptors targeted in systemic RCC and in ocular tissue; similarly a comparison can be drawn between pazopanib and its effects on ocular tissues. With pazopanib's large bioavailability in ocular tissues, and its direct effect on VEGF receptors - there can be a correlation made between pazopanib and retinal tears developing after initiating chemotherapy. Retinal tears occur when the retinal tissue begins to peel away from supporting tissue. Rhegmatogenous retinal detachment, the type of retinal attachment the patient in above case had, occurs primarily when a small retinal tear allows for fluid to pass from vitreous space into subretinal space where the retinal pigment epithelium (RPE) is located. Studies have illustrated that these tears are often preceded by anti-VEGF therapy, stating that an "increased risk of developing a retinal pigment epithelium tear after anti-VEGF therapy" is common in many patients. " This occurs because following the administration of anti-VEGF therapy, there is rapid involution and contraction of the neovascular tissue that is attached to the undersurface of the retinal pigment epithelium. Those forces will cause a contractile force of the RPE forcing a tear on the retinal tissue. ${ }^{12}$ Given the pathophysiology of retinal tears and its relationship with anti-VEGF therapy - it is highly probable that the repeated administration of pazopanib in therapeutic doses for RCC can lead to strain of the retinal pigment epithelium, inducing a tear and further progressing onto a rhegmatogenous retinal detachment.

\section{KEY POINTS}

This case illustrates a risk with using VEGF inhibitors, such as pazopanib, due to the possibility of retinal damage causing tears leading to detachment. As in our case, there is an increased amount of anti-VEGF being used in renal cell carcinoma cases at therapeutic doses. With the increased usage, guidelines may be required for annual ophthalmology screening to monitor for retinal abnormalities. Furthermore, follow up will be required to determine if discontinuing the pazopanib and starting Sutent helped deter further ocular abnormalities. Overall, it should be recommended to discontinue pazopanib if any blurry vision or vision changes are noted. 


\section{REFERENCES}

1. Rini, B. I., Campbell, S. C., \& Escudier, B. "Renal Cell Carcinoma." The Lancet. 2009; 373(9669), 1119-1132.

2. Gupta, K., Miller, J. D., Li, J. Z., Russell, M. W., \& Charbonneau, C. "Epidemiologic and socioeconomic burden of metastatic renal cell carcinoma (mRCC): a literature review." Cancer Treatment Reviews. 2008; 34(3), 193-205.

3. Hutson, T. E. "Targeted therapies for the treatment of metastatic renal cell carcinoma: clinical evidence." The Oncologist, 2011; 16(2), 14-22.

4. Gernone, A. "Experience with pazopanib in the treatment of metastatic renal cell carcinoma: a monocentric experience." Tumori. 2014; 100(4), 165e-8e.

5. Gaertner, K. M., Caldwell, S. H., \& Rahma, O. E. "A Case of Retinal Tear Associated with Use of Sorafenib." Frontier Oncology. 2014; 4(196)

6. Wegner, A., \& Khoramnia, R. "Neurosensory retinal detachment due to sunitinib treatment." Eye. 2011; 25, 1517-1518.

7. Sternberg, C. N., Davis, I. D., Mardiak, J., Szczylik, C., Lee, E. Wagstaff, J., \& Barrios, C. H. "Pazopanib in Locally Advanced or Metastatic Renal Cell Carcinoma: Results of a Randomized Phase III Trial." Journal of Clinical Oncology. 2010; 28(6), 1061-1068.
8. Yafai, Y., Yang, X. M., Niemeyer, M., Nishiwaki, A., Lange, J. Wiedemann, P., \& King, A. G. "Anti-angiogenic effects of the receptor tyrosine kinase inhibitor, pazopanib, on choroidal neovascularization in rats." European Journal of Pharmacology. 2011; 666(1-3), 12-18.

9. Takahashin, K., Saishin, Y., Saishin, Y., King, A. G., Levin, R., \& Campochiaro, P. A. "Suppression and Regression of Choroidal Neovascularization by the Multitargeted Kinase Inhibitor Pazopanib." JAMA Opthalmology. 2009; 127(4), 494-499.

10. Kumar, R., Knick, V. B., Rudolph, S. K., Johnson, J. H., Crosby, R. M., Crouthamel, M.-C., . Epperly, A. H. "Pharmacokineticpharmacodynamic correlation from mouse to human with pazopanib, a multikinase angiogenesis inhibitor with potent antitumor and antiangiogenic activity". Molecular Cancer Therapy. 2007; 6

11. Chiang, A., Chang, L., Yu, F., \& Sarraf, D. "Predictors of anti-VEGFassociated retinal pigment epithelial tear using FA and OCT analysis." Retina. 2008; 28(9), 1265-1269.

12. Nagiel, A., Freund, B., Spaide, R. F., Munch, I. C., Larsen M., \& Sarraf, D. "Mechanism of Retinal Pigment Epithelium Tear Formation Following Intravitreal Anti-Vascular Endothelial Growth Factor Therapy Revealed by Spectral-Domain Optical Coherence Tomography." American Journal of Opthalmology. 2013: 156(6), 981-988.

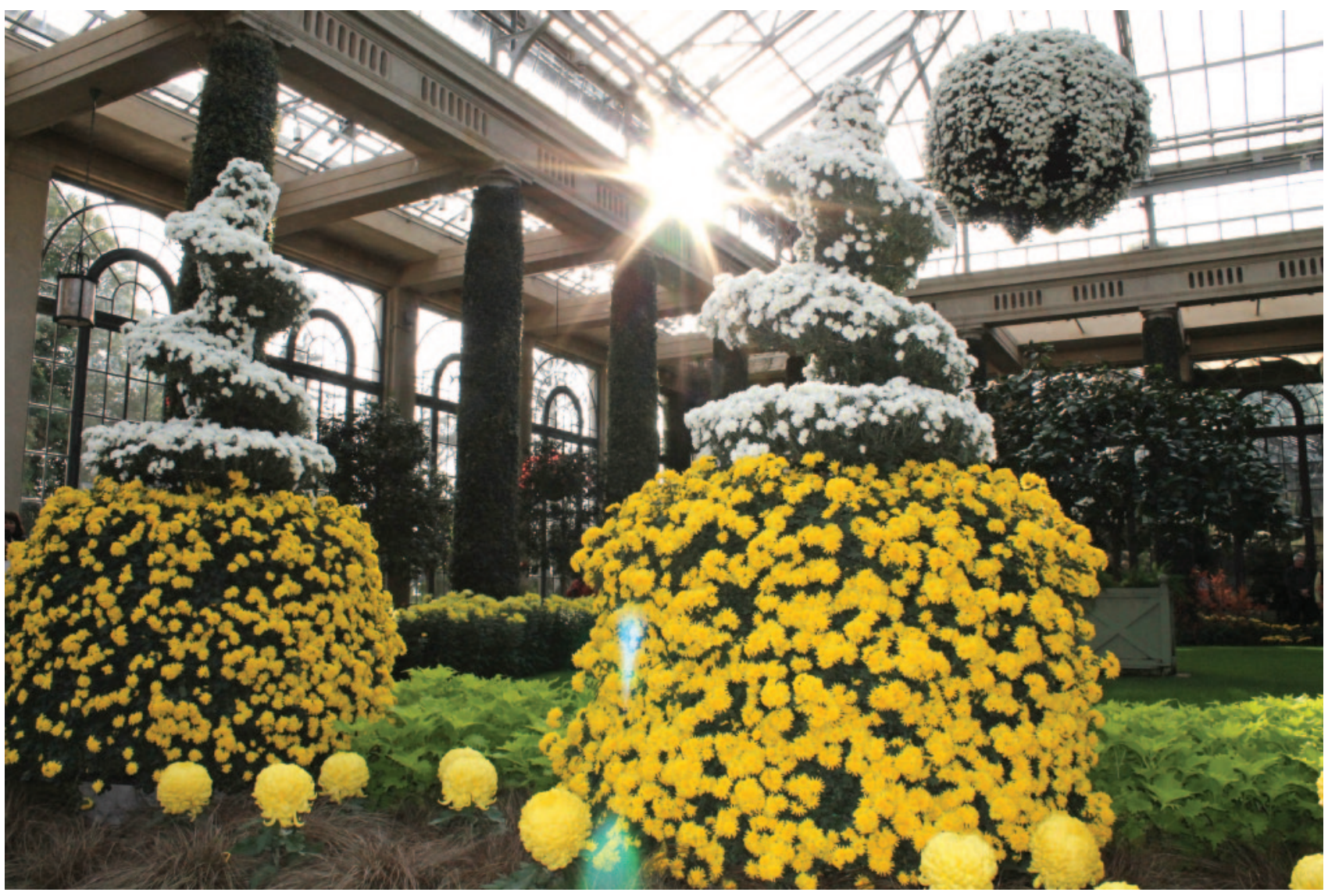

